\title{
Effect of Paper Type and Water Content in Paper on the Partitioning of 2-FAL between Liquid and Paper Insulations
}

\author{
Shanika Yasantha Matharage \\ The University of Manchester \\ Manchester M13 9PL, United Kingdom \\ shanika.matharage@manchester.ac.uk
}

\author{
Qiang Liu* \\ The University of Manchester \\ Manchester M13 9PL, United Kingdom \\ qiang.liu@manchester.ac.uk \\ David Walker \\ Scottish Power \\ Blantyre G72 0HT, United Kingdom \\ David.Walker2@spenergynetworks.co.
}

\author{
Zhongdong Wang \\ The University of Manchester \\ Manchester M13 9PL, United Kingdom \\ zhongdong.wang@manchester.ac.uk
}

\begin{abstract}
For nearly four decades 2-furfural (2-FAL) in transformer oil has been used as a chemical marker to indicate the ageing state of transformer paper insulation. Nevertheless, it has always been a challenge to define an acceptable limit for 2-FAL due to issues related to non-uniform temperature distribution in transformers, stability of 2-FAL in oil and its partitioning between liquid and solid insulation. Therefore, transformer users try to combine the laboratory findings, the operational experience and post-mortem analyses together for predicting ageing state of paper insulation through 2-FAL content in oil. Due to increase in the use of ester liquids in transformers, there is a need to investigate the ability to use 2-FAL as a paper ageing indicator for ester based insulation systems. Laboratory ageing studies have shown that 2-FAL is indeed generated in ester based insulation systems. However, there is a lack of understanding related to the partitioning of 2-FAL in ester based insulation systems. This paper studies the partitioning of 2-FAL in synthetic ester based insulation systems and compares to that in mineral oil based insulation systems with the focus on the effect of paper type and water content in paper. Under the investigated conditions the synthetic ester had higher partitioning coefficients (ratio between the 2-FAL content in oil and paper) than the mineral oil. Partitioning coefficients in both oil types decreased with the increase of the water content in paper. However, change in paper type did not significantly affect the partitioning coefficients in this study.
\end{abstract} paper

Keywords-furfural, mineral oil, synthetic ester, partitioning,

\section{INTRODUCTION}

Degradation of paper insulation is considered to be one of the main reasons for the ageing related failures of transformers due to the irreversible ageing nature and the difficulties involved with replacement. Therefore, it is important to monitor the ageing state of paper insulation to avoid failures and unplanned outages. However, due to poor accessibility it is nearly impossible to assess the ageing state of paper insulation through direct measurements of paper such as tensile strength or degree of polymerisation (DP). Hence, it is common to estimate the ageing state of paper insulation through chemical markers in oil that are predominantly generated from paper-ageing. Furanic compounds, carbon oxide gases, low molecular weight alcohols and acids are some of the chemical markers related to paper ageing [1].
The use of furanic compounds as chemical markers for paper insulation was first proposed in early 1980s [2]. Currently, there are two main international standards available for measuring furanic compounds through high performance liquid chromatography (HPLC) technique: ASTM D5837 standard and IEC 61198 standard. Out of different furanic compounds, 2-furfural (2-FAL) is related to general ageing of paper insulation and typically is the most abundant furanic compound found in transformers in-service [3, 4]. Experiments have shown that 2-FAL in transformers is generated from components of paper insulation and its ageing products including cellulose, pentosans and leveoglucosan [5].

Over the years, different models have been proposed to predict the ageing state of paper insulation through 2-FAL measurement in oil. These have been developed based on laboratory experiments and theoretical analysis [6, 7]. However, these models often disagree with each other [7] and hence users may struggle with selecting a model to predict DP of the transformer paper insulation. In addition to the non-uniform ageing of paper insulation, issues related to the stability of 2-FAL and its partitioning process further complicates the prediction of the ageing state of paper insulation through 2-FAL measurement. The lack of any international standard that defines acceptable limits for 2-FAL in transformer have enforced users to develop their own criteria based on the experience from their transformer fleets and post-mortem analysis. CIGRE working group that studied about furanic compounds has suggested to study subsets that represent similar equipment with regard to 2-FAL generation and materials (such as thermally upgraded / non thermally upgraded and sealed / free breathing) when obtaining abnormal 2-FAL levels [7]. Such analysis conducted with 78 scrapped transmission transformers from the UK transmission system has shown that 2-FAL content of about 2 to $3 \mathrm{ppm}$ is an indication of the DP reduction towards 200 in that transformer fleet [8].

Understanding stability and partitioning process of 2-FAL are the two key factors for improving the reliability of the 2FAL based DP prediction models. Experiments have shown that under non-oxidative conditions $2-\mathrm{FAL}$ is stable at transformer operating temperatures up to about $110{ }^{\circ} \mathrm{C}$ [9]. Furthermore, some studies have shown that factors such as oxygen [10], copper and di-cy compounds found in thermally 
upgraded paper [11] could also reduce the stability of 2-FAL in transformer oil. In addition to the loss of 2-FAL through chemical reactions, 2-FAL content in oil could change considerably during oil reclamation [12].

Many researchers have studied the partitioning of 2-FAL in an insulation system and factors that influence the process. Studies so far have shown that partitioning of 2-FAL could be affected by factors including temperature and water content $[4,7,13,14]$. Typically, temperature increase results in an increase in the 2-FAL content in oil [13]. However, the amount of increase is considerably lower than other polar chemical-markers such as water. Partitioning study with a model transformer has shown that an increase in temperature from $20{ }^{\circ} \mathrm{C}$ to $90{ }^{\circ} \mathrm{C}$ would only double the 2-FAL content in oil compared to moisture content which increased by almost 16 times [13].

Water content in the insulation system is another parameter that affects the partitioning of 2-FAL between oil and paper. It is generally understood that 2-FAL would follow the direction of water within an insulation system [7]. Laboratory ageing experiments have shown that the relationship between DP of paper and 2-FAL content in oil depends on the initial water content in paper [14]. Furthermore, some in-service measurements have shown that the 2-FAL content in oil is inversely proportional to the relative water content in oil [4].

Due to the increasing use of ester liquids, there is a need to understand the ability to use 2-FAL as a paper ageing indicator for transformers filled with ester liquids. Measurable quantities of 2-FAL has been measured during laboratory ageing experiments conducted with Kraft paper and synthetic ester [15]. However, there is a lack of studies into the partitioning of 2-FAL in ester based insulation systems. This paper investigates the partitioning of 2-FAL in ester based insulation systems compared to that of mineral oil based systems with the focus on factors including paper type and the water content in paper.

\section{EXPERIMENTAL DESCRIPTION}

Partitioning of 2-FAL was studied using two liquid types and two paper types. The two liquids are: a synthetic ester (MIDEL 7131) and an inhibited mineral oil (Gemini X), and the two paper types are: thermally upgraded (TU) Kraft paper and non-thermally upgraded (NTU) Kraft paper manufactured by WEIDMANN. Both paper types have similar width $(1.5$ $\mathrm{cm})$, thickness $(0.005 \mathrm{~cm})$ and apparent density values $(0.84$ $\left.\mathrm{g} / \mathrm{cm}^{3}\right)$. Paper strips of $53 \mathrm{~cm}$ in length and a volume of $0.4 \mathrm{~cm}^{3}$ were used in the experiment.

\section{A. Sample Preparation}

Insulating liquid was first dehydrated by purging with nitrogen. Moisture content in dried synthetic ester was about $65 \mathrm{ppm}$ and in mineral oil it was about $6 \mathrm{ppm}$. Part of the dried synthetic ester and mineral oil was spiked with 2-furfural to obtain nearly $5 \mathrm{ppm}$ of $2-\mathrm{FAL}$ content in liquid while the rest was used for the paper impregnation process.

Paper strips were first dried at $105{ }^{\circ} \mathrm{C}$ under vacuum of less than $500 \mathrm{~Pa}$ for 72 hours. Next, temperature of the vacuum oven was reduced to $60{ }^{\circ} \mathrm{C}$ and dried insulating liquid was added into the chamber under vacuum. Samples were left inside the vacuum oven for 48 hours to allow the impregnation of paper. Once the impregnation was completed, samples were cooled down to room temperature. The paper samples were then transferred into a funnel and left under vacuum for further 24 hours to drain excess liquid from paper. The procedure was used to impregnate both TU and NTU Kraft paper samples in mineral oil and synthetic ester.

1) Preparation of samples with a low water content in paper:

Samples were prepared by combining each liquid-impregnated paper strip with $8 \mathrm{ml}$ of insulating liquid in a headspace vial. Table I shows the water content in paper and the 2-FAL content in liquid for the samples prepared with a low water content in paper.

TABLE I. INITIAL WATER CONTENT IN PAPER AND 2-FAL CONTENT IN LIQUID PREPARED WITH A LOW WATER CONTENT IN PAPER

\begin{tabular}{|c|c|c|c|}
\hline Oil type & \multirow{2}{*}{$\begin{array}{c}\text { 2-FAL content } \\
\text { in liquid (ppm) }\end{array}$} & \multicolumn{2}{|c|}{ Water content in paper } \\
\cline { 3 - 4 } & & NTU Kraft & TU Kraft \\
\hline Mineral oil & 4.65 & $0.25 \%$ & $0.15 \%$ \\
\hline Synthetic ester & 4.58 & $1.08 \%$ & $0.62 \%$ \\
\hline
\end{tabular}

\section{2) Preparation of samples with a high water content in} paper:

The liquid-impregnated paper samples were first left at room condition of about $20{ }^{\circ} \mathrm{C}$ temperature and about $40 \%$ relative humidity for a week to absorb moisture into paper. At the end of the conditioning period, each paper sample was combined with $8 \mathrm{ml}$ of insulating liquid spiked with 2-FAL in a headspace vial. Table II shows the initial water content in paper and the 2-FAL content in liquid for the samples prepared with a high water content in paper. It can be seen that under the same temperature and relative humidity conditions TU Kraft paper has a lower water content than NTU Kraft paper which has been observed during other experiments [16].

TABLE II. INITIAL WATER CONTENT IN PAPER AND 2-FAL CONTENT IN LIQUID PREPARED WITH A HIGH WATER CONTENT IN PAPER

\begin{tabular}{|c|c|c|c|}
\hline Oil type & $\begin{array}{c}\text { 2-FAL content } \\
\text { in liquid (ppm) }\end{array}$ & \multicolumn{2}{|c|}{ Water content in paper } \\
\cline { 3 - 4 } & & NTU Kraft & TU Kraft \\
\hline Mineral oil & 5.34 & $6.85 \%$ & $4.45 \%$ \\
\hline Synthetic ester & 4.83 & $5.45 \%$ & $3.52 \%$ \\
\hline
\end{tabular}

Once prepared, samples were sealed with crimped-caps and left at room temperature of $20{ }^{\circ} \mathrm{C}$ to allow 2-FAL to partition between liquid and paper insulations. Two samples were taken at each sampling period and the remaining 2-FAL content in liquid was measured through HPLC following the direct injection technique according to ASTM D5837 standard. With the direct injection technique, 2-FAL content in mineral oil and synthetic ester can be measured using a single calibration curve compared to indirect injection technique which requires separate calibration curves for two liquid types [15]. Partitioning studies were conducted for up to 100 and 300 days for the samples with a low water content in paper and a high water content in paper, respectively.

\section{RESULTS AND DISCUSSIONS}

\section{A. Partitioning of 2-FAL in samples with a low water content in paper}

Fig. 1. shows the variation of 2-FAL content in mineral oil and synthetic ester when combined with paper that has a low water content. 2-FAL content in all the four combinations of 
samples has shown a slight reduction during the first 40 days of the conditioning period and stabilized for the rest of the period. At the end of 100-day period, 2-FAL content in mineral oil combined with both NTU and TU Kraft papers has reduced by $10 \%$ and $8 \%$, respectively. On the other hand, 2FAL content in synthetic ester combined with NTU and TU Kraft papers has reduced only by $5 \%$ and $4 \%$, respectively.

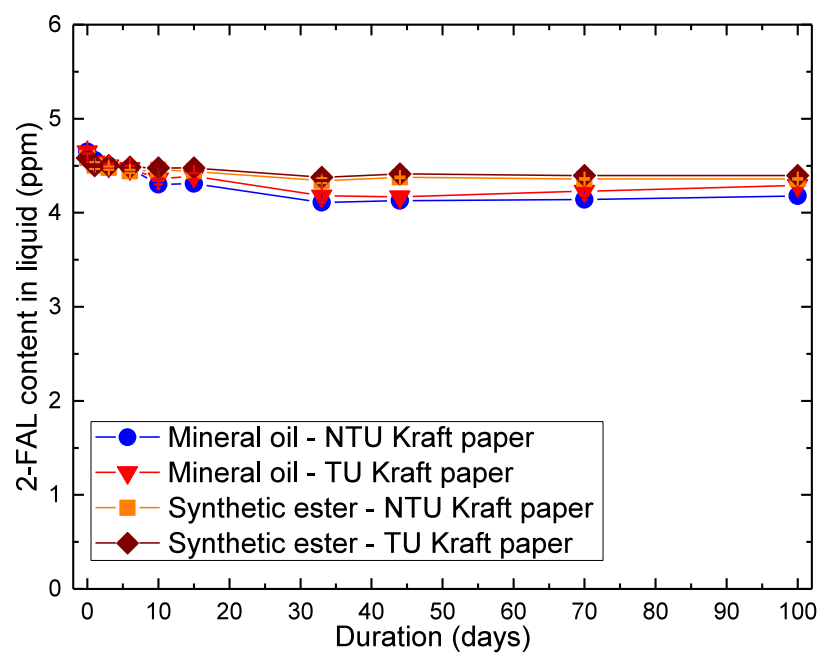

Fig. 1. Variation in the 2-FAL content in liquid for samples with a low water content in paper

\section{B. Partitioning of 2-FAL in samples with a high water content in paper}

Fig. 2. shows the variation of 2-FAL content in mineral oil and synthetic ester when combined with NTU and TU Kraft paper with a high water content. Within about first 50 days, 2FAL content in mineral oil decreased in a faster rate than that in synthetic ester. The rate of reduction in all four sample types has considerably reduced after 200 days indicating that the 2-FAL content in oil has either reached or close to reaching the equilibrium state. Samples with mineral oil combined with NTU Kraft paper showed the largest percentage of 2-FAL reduction in liquid while the samples with synthetic ester and TU Kraft paper showed the smallest percentage of 2-FAL reduction.

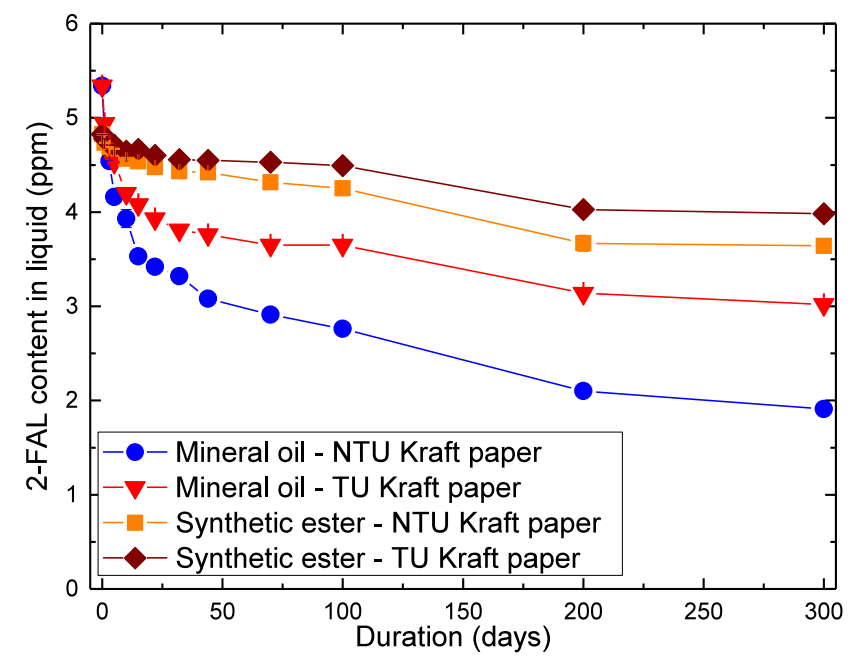

Fig. 2. Variation in the 2-FAL content in liquid for samples with a high water content in paper

\section{Effect of liquid type, paper type and water content in paper on the partitioning of 2-FAL between liquid and paper}

Fig. 3. compares the percentage of 2-FAL content retained in liquid at the end of the conditioning periods. It can be seen that this percentage varies between $36 \%$ and $96 \%$. The smallest percentage of 2-FAL retained in oil was observed in mineral oil when combined with NTU Kraft paper with a high water content whereas the largest percentage retained in liquid was seen in synthetic ester when combined with TU Kraft paper with a low water content. Furthermore, increase in the water content in paper, has resulted in an increase in the migration of 2-FAL from liquid to paper. Generally, percentage of 2-FAL content retained in synthetic ester is higher than the respective percentage in mineral oil.

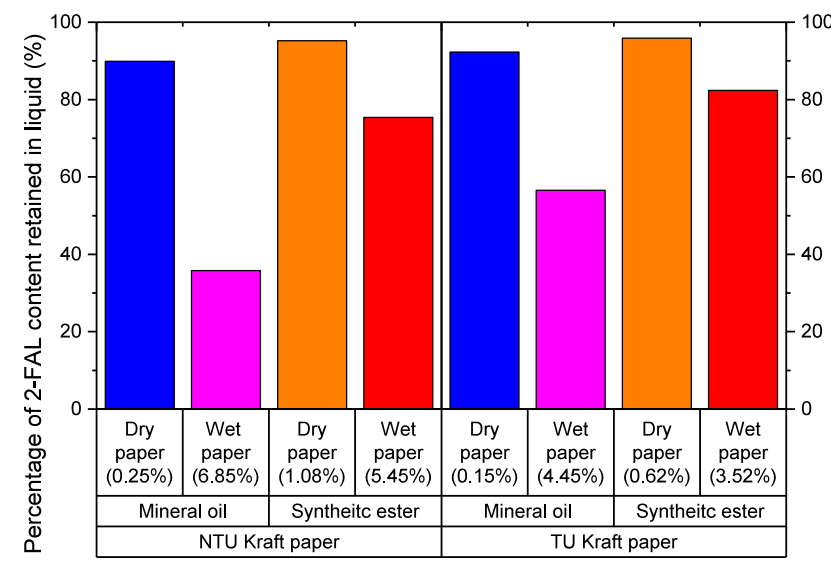

Fig. 3. Percentage of 2-FAL retained in the liquid at the end of conditioning periods

Fig. 4. shows the partitioning coefficients calculated for each combination against its initial water content in paper. Partitioning coefficients were calculated following (1) as a ratio between the 2-FAL content in liquid and the 2-FAL content in paper at the end of the conditioning period.

$$
\frac{[2-F A L]_{\text {final }}}{\left(20 \times[2-F A L]_{\text {initial }}-[2-F A L]_{\text {final }}\right)}
$$

In (1), $[2-F A L]_{\text {initial }}$ is the initial 2 -FAL content in liquid and $[2-F A L]_{\text {final }}$ is the $2-F A L$ content in liquid at the end of the conditioning period. The multiplication factor 20 represents the volume ratio between oil and paper. It was assumed that 2-FAL content in the samples reached an equilibrium at the end of the conditioning period and the amount of 2-FAL decreased from the liquid moved into the paper. Partitioning coefficients for all combinations except for the combinations of synthetic ester and paper with a low water content were less than one, which indicates that in those combinations 2-FAL content in paper is higher than liquid. Furthermore, partitioning coefficients in all four liquid-paper combinations decreased with the increase in water content, which is in line with the current understanding of 2-FAL following water in the insulation system [7].

Furthermore, two different trend lines can be identified for the partitioning coefficients for mineral oil and synthetic esters, out of which the trend line for synthetic ester is above the mineral oil. The polar nature of synthetic ester could have attracted more 2-FAL than mineral oil resulting in a higher partitioning coefficient than mineral oil. A similar 
phenomenon was observed during a partitioning study conducted with methanol in which synthetic ester attracted more methanol than mineral oil [15]. It can also be seen that the partitioning coefficient reduction trend for synthetic ester has a similar gradient to that of mineral oil and the type of paper has a negligible effect on the relationship between the partitioning coefficient and water content in paper. However, more experiments with different water content levels in paper would help to verify these phenomena.

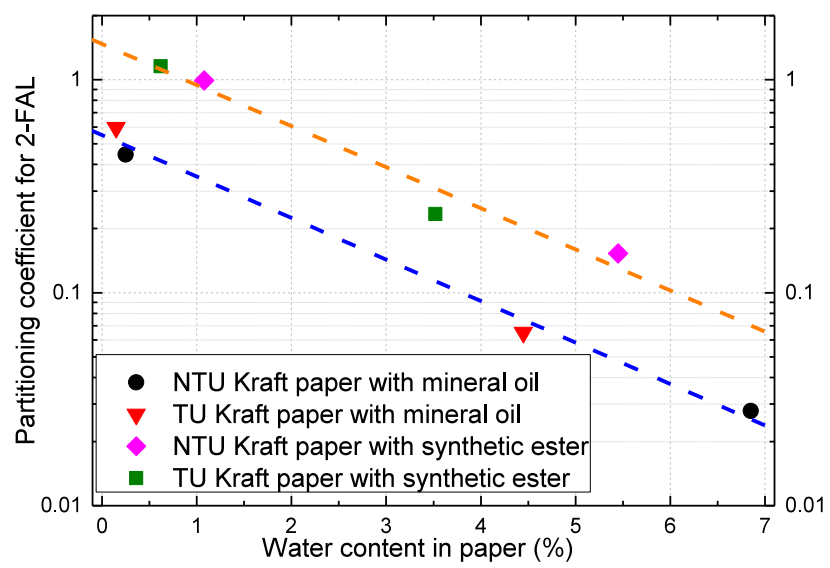

Fig. 4. Variation in the partitioning coefficients for 2-FAL against the initial water content in paper

\section{CONCLUSIONS}

This paper investigates the effect of paper type and the water content in paper on the partitioning process of 2-FAL in synthetic ester-paper insulation systems as well as mineral oil-paper insulation systems. Samples prepared with paper and insulating liquid were spiked with 2-FAL, and conditioned at room temperature to monitor the retained 2-FAL content in the liquid. The measurement results showed that the partitioning process of 2-FAL in the insulation system with synthetic ester is different from the insulation system with mineral oil. Under the investigated conditions synthetic esters retained more 2-FAL than mineral oil and hence had higher partitioning coefficients than mineral oil. Furthermore, the partitioning coefficients for 2-FAL decreased with the increase in water content but the relationship was independent from the paper type.

\section{ACKNOWLEDGMENT}

The authors would like to express their gratitude to EPRI, M\&I Materials, National Grid, Scottish Power, SGB-SMIT, Shell, TJ $\mid \mathrm{H} 2 \mathrm{~b}$ and Weidmann for their financial and technical contributions to the Transformer Research Consortium at The University of Manchester.

\section{REFERENCES}

[1] Cigre Brochure No 738: Ageing of liquid impregnated cellulose for power transformers, 2018

[2] P. J. Burton, J. Graham, A. C. Hall, J. A. Laver, and A. J. Oliver, "Recent developments by CEGB to improve the predictions and monitoring of transformer performance," CIGER International Conference on Large Highvoltage Electric Systems, Paris, 1984.

[3] R. D. Stebbins, D. S. Myers, and A. B. Shkolnik, "Furanic compounds in dielectric liquid samples: review and update of diagnostic interpretation and estimation of insulation ageing," $7^{\text {th }}$ International Conference on Properties and Applications of Dielectric Materials, vol.3, pp. 921-926, 2003.

[4] J. R. Sans, K. M. Bilgin, and J. J. Kelly, "Large-scale survey of furanic compounds in operating transformers and implications for estimating service life," IEEE International Symposium on Electrical Insulation, vol. 2, pp. 543-553, 1998.

[5] J. Scheirs, G. Camino, M. Avidano, and W. Tumiatti, "Origin of furanic compounds in thermal degradation of cellulosic insulating paper," Journal of Applied Polymer Science, vol. 69, no. 13, pp. 2541-2547, 1998.

[6] D. Feng, Z.D. Wang, and P. Jarman, "Transmission power transformer assessment using furan measurement with the aid of thermal model," International Conference on Condition Monitoring and Diagnosis (CMD), pp. 521-524, 2012.

[7] Cigre Brochure No 494: Furanic compounds for diagnosis, 2012.

[8] J. Lapworth, H. Z. Ding, S. Ryder, and P. Jarman, "Progress towards a reliable transformer service life prediction," 78th Annual International Doble Client Conference, Bostan, MA, USA, 2011.

[9] D. Allan, "Recent advances in the analysis and interpretation of aged insulation from operating power transformers," $5^{\text {th }}$ International Conference on Properties and Applications of Dielectric Materials, Seoul, South Korea, pp. 202-205, 1997.

[10] A. M. Emsley, X. Xiao, R. J. Heywood, and M. Ali, "Degradation of cellulosic insulation in power transformers. Part 2: formation of furan products in insulating oil," IEE Proceedings - Science, Measurement and Technology, vol. 147, no. 3, pp. 110-114, 2000.

[11] P. J. Griffin, L. R. Lewand, and B. Pahlavanpour, "The analysis of paper degradation by-products as a tool for monitoring fault conditions in oil-filled electric apparatus," $2^{\text {nd }}$ International Conference on the Reliability of Transmission and Distribution Equipment, pp. 79-84, 1995.

[12] Z.D. Wang, Q. Liu, S. J. Tee, S. Y. Matharage, P. Jarman, G. Wilson, R. Hooton, P. Dyer, D. Walker, C. Krause, P. W. R. Smith, P. Mavrommatis and A. Gyore, "Ageing Assessment of Transformers through Oil Test Database Analyses and Alternative Diagnostic Techniques," CIGRE SC A2 Colloquium, Shanghai, China, 2015.

[13] M. C. Lessard, J. Jalbert, and M. Ryadi, "Establishing correction factors for the partitioning of furanic derivatives between oil and paper insulation," IEEE Conference on Electrical Insulation and Dielectric Phenomena (CEIDP), pp. 132-135, 2013.

[14] I. Hohlein and A. J. Kachler, "Aging of cellulose at transformer service temperatures. Part 2. Influence of moisture and temperature on degree of polymerization and formation of furanic compounds in freebreathing systems," IEEE Electrical Insulation Magazine, vol. 21, no. 5, pp. 20-24, 2005.

[15] S. Y. Matharage, Q. Liu, Z.D. Wang, G. Wilson, and C. Krause, "Aging assessment of synthetic ester impregnated thermally non-upgraded kraft paper through chemical markers in oil," IEEE Transactions on Dielectrics and Electrical Insulation, vol. 25, no. 2, pp. 507-515, 2018.

[16] M. Koch, S. Tenbohlen, and T. Stirl, "Diagnostic application of moisture equilibrium for power transformers," IEEE Transactions on Power Delivery, vol. 25, no. 4, pp. 2574-2581, 2010. 